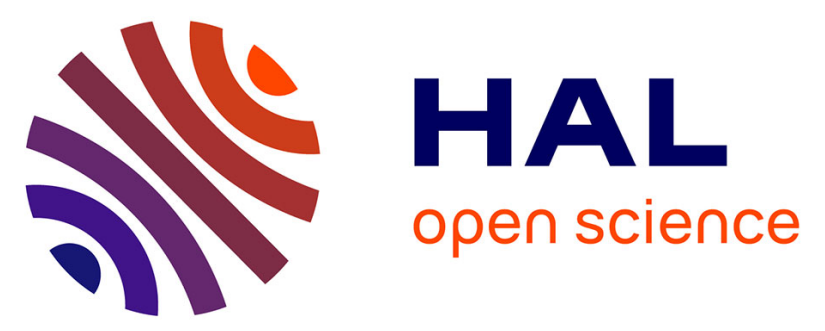

\title{
Morphological variability of choanocyte kinetids supports a novel systematic division within Oscarellidae (Porifera, Homoscleromorpha)
}

Pozdnyakov Igor, Sokolova Agniya, Karpov Sergey, Cesar Ruiz, Thierry Perez, Ekimova Irina, Alexander Ereskovsky

\section{To cite this version:}

Pozdnyakov Igor, Sokolova Agniya, Karpov Sergey, Cesar Ruiz, Thierry Perez, et al.. Morphological variability of choanocyte kinetids supports a novel systematic division within Oscarellidae (Porifera, Homoscleromorpha). Journal of Zoological Systematics and Evolutionary Research, 2021, 59, pp.3143. 10.1111/jzs.12417 . hal-02944742

\section{HAL Id: hal-02944742 \\ https://hal.science/hal-02944742}

Submitted on 4 Dec 2020

HAL is a multi-disciplinary open access archive for the deposit and dissemination of scientific research documents, whether they are published or not. The documents may come from teaching and research institutions in France or abroad, or from public or private research centers.
L'archive ouverte pluridisciplinaire HAL, est destinée au dépôt et à la diffusion de documents scientifiques de niveau recherche, publiés ou non, émanant des établissements d'enseignement et de recherche français ou étrangers, des laboratoires publics ou privés. 


\section{Morphological variability of choanocyte kinetids supports a novel systematic division within Oscarellidae (Porifera, Homoscleromorpha)}

Choanocyte kinetids in Oscarellidae

Pozdnyakov Igor ${ }^{1}$, Sokolova Agniya ${ }^{3}$, Karpov Sergey ${ }^{1,2}$, Ruiz César $^{4}$, Pérez Thierry ${ }^{4}$, Ekimova Irina $^{5}$, Ereskovsky Alexander ${ }^{3,4,6}$

${ }^{1}$ Zoological Institute of Russian Academy of Sciences, Universitetskaya nab. 1, St. Petersburg, 199034 Russia.

${ }^{2}$ Department of Invertebrate Zoology, Biological Faculty, St. Petersburg State University, Universitetskaya nab. 7/9, St. Petersburg, 199034 Russia

${ }^{3}$ Koltzov Institute of Developmental Biology of Russian Academy of Sciences, Vavilova ul., 26, Moscow, 119334 Russia

${ }^{4}$ Mediterranean Institute of Marine and Terrestrial Biodiversity and Ecology (IMBE), Aix Marseille University, CNRS, IRD, Avignon University, Station marine d'Endoume, rue de la Batterie des Lions, 13007 Marseille France

${ }^{5}$ Department of Invertebrate Zoology, Lomonosov Moscow State University, 119234 Leninskie gory 1-12, Moscow Russia

${ }^{6}$ Department of Embryology, Biological Faculty, St. Petersburg State University, Universitetskaya nab. 7/9,St. Petersburg, 199034 Russia

Corresponding author:

Pozdnyakov Igor

199034, St.-Petersburg, Russia, Universitetskaya nab., 1, Zoological institute of RAS

d_igor_po@yahoo.com

Keywords: sponges, Oscarella, choanocytes, systematics, kinetid 


\begin{abstract}
Homoscleromorpha is a recently recognized class within the phylum Porifera. While molecular analyses support monophyly of Homoscleromorpha, morphological data are largely lacking. Here we investigate and comparatively analyze the detailed morphology of kinetids (flagellar apparatus) in choanocytes of ten Oscarella species. The kinetid is known to be a phylogenetically important trait that can possibly reflect relationships of sponges at the level of orders. We also conduct a phylogenetic analysis based on previously published sequences. We found the family Oscarellidae is subdivided into two large groups, and choanocyte kinetids structure strongly supports this division. The first group includes $O$. lobularis, O. tuberculata, O. bergenensis, O. viridis, O. rubra, O. malakhovi, O. microlobata, O. carmela, O. filipoi and $O$. zoranja. These species possess nuclei located in a basal position without any connection to the kinetosome. The second group includes $O$. balibaloi, O. nicolae, O. kamchatkensis, O. pearsei, O. imperialis, and Pseudocorticium jarrei, whose nuclei are connected with the kinetosome. In addition, this second group also shares mesohylar spherulous cells harboring paracrystalline inclusions. The choanocyte kinetid structure seems to be an essential phylogenetic and diagnostic morphological trait, and we propose to include it in future species descriptions. Our results imply assignation of the second group to the genus Pseudocorticium. This taxonomic suggestion, however, needs additional data on the remaining Oscarella species..
\end{abstract}




\section{Introduction}

In the last fifteen years, the taxonomy and systematics of the phylum Porifera underwent tremendous changes. The three sponge classes, Demospongiae, Calcarea and Hexactinellida, was complemented by a fourth group, the Homoscleromorpha. It was elevated to the rank of class according to molecular systematics' studies and re-examination of cytological traits such as flagellated exo- and endopinacocytes, a basement membrane lining both choanoderm and pinacoderm, and the presence of peculiar flagellated apopylar cells (Gazave et al. 2012). Integrative systematics justified the subdivision of the single order of this class into two families (Gazave et al., 2010; Ivanišević et al., 2011; Boury-Esnault, Lavrov, Ruiz, \& Pérez, 2013), namely the Plakinidae with a spiculate skeleton and the Oscarellidae without skeleton. Currently, this very simple subdivision has become a matter of debate, especially after the discovery of several members of Plakinidae without skeleton (Ruiz et al., 2017). Additional morphological characters could help clarifying Homoscleromorpha systematics.

The flagellum with its basal intracellular part (is called kinetid or flagellar apparatus) has been shown to be an important source of phylogenetic information in a number of taxa (Barr, 1981; Melkonian, 1982; Moestrup, 1982, 2000; O'Kelly, \& Floyd, 1983; Karpov, 1988, 2000, 2016; Andersen et al., 1991; Baldauf, 1999; Cavalier-Smith, 2000, 2013; Dewel, Connell, \& Dewel, 2003; Letcher et al., 2005; Yubuki, \& Leander, 2013). The kinetid of sponge choanocyte consists of three main parts: (1) a free part, or flagellum, containing an axoneme; (2) a basal intracellular part; and (3) the transition zone connecting the free and basal parts. The basal intracellular part normally comprises a flagellar basal body (= kinetosome), nine transition fibers attaching the distal part of the kinetosome to the plasma membrane, a basal foot (conical shaped body), lateral microtubules radiating from the foot, a centriole (non-flagellar kinetosome) and fibrillar roots (bundles of fibrils of different lengths) deriving from the kinetosome or, more rarely, from the centriole (Fig. 1). In sponges, the choanocyte kinetid is regarded as a potentialmorphological phylogenetic marker, as it includes evolutionary conservative structures along with variable ones (Pozdnyakov, Sokolova, Ereskovsky, \& Karpov, 2017, 2018).

At the end of the $19^{\text {th }}$ century, Minchin (1896) and Bidder (1898) proposed a classification of calcareous sponges based on the cytological traits of their choanocytes, in particular the position of the nucleus and its relation to the flagellum (connected or not connected). This morphology-based classification was confirmed a century later by molecular analyses (Manuel et al., 2003; Manuel, 
2006). The relevance of these two features related to the kinetid structure was discussed for Demospongiae (Pozdnyakov, \& Karpov, 2016a, 2016b; Pozdnyakov et al., 2017, 2018), but so far has not been extended to the Homoscleromorpha, although cytological observations are essential to describe the diversity of Oscarellidae.

We provide here a detailed description of the choanocyte kinetid structure of two Oscarella species, Oscarella lobularis (Schmidt, 1862) and Oscarella balibaloi Pérez, Ivanišević, Dubois, Pedel, Thomas, Tokina, \& Ereskovsky, 2011 (Homoscleromorpha, Oscarellidae), accompanied by data on the nucleus position within the choanocyte in eight other Oscarella species. Comparing morphological and genetic data, we aim to assess the relevance of this cytological trait to support the current inter-specific relationships among the family Oscarellidae.

\section{Materials and methods}

\section{Material collection}

Sponge specimens were sampled by SCUBA diving. Oscarella balibaloi Pérez, Ivanisevic, Dubois, Pedel, Thomas, Tokina \& Ereskovsky, 2011, O. lobularis (Schmidt, 1862) and O. tuberculata (Schmidt, 1868) were collected in the NW Mediterranean Sea at Maïre Island (France), O. viridis Muricy, Boury-Esnault, Bézac, \& Vacelet, 1996, O. microlobata Muricy, Boury-Esnault, Bézac, \& Vacelet, 1996 and Pseudocorticium jarrei Boury-Esnault, Muricy, Gallissian, \& Vacelet, 1995 in the Jarre Cave, Marseille (France), Oscarella rubra (Hanitsch, 1980) near Roscoff (NW France), $O$. carmela Muricy, \& Pearse, 2004 and O. pearsei Ereskovsky, Richter, Lavrov, Schippers, \& Nichols, 2017 at Long Marine Laboratory of the University of California (Santa Cruz, USA), O. malakhovi Ereskovsky, 2006 in the Sea of Japan, Vostok Bay (Russia), and O. kamchatkensis Ereskovsky, Sanamyan, \& Vishnyakov, 2009 in Avacha Gulf, Pacific Coast of the Kamchatka Peninsula (Russia). Oscarella rubra is currently not accepted in the World Porifera Database where it is classified as a member of the genus Aplysilla (Van Soest et al. 2019). However, this species was included in this study because our morphological (our non-published date) and genetical analysis clearly shows that it belongs to the genus Oscarella (Gazave et al. 2013), which is in accordance with the original description of this species by Hanitsch (1890).

\section{Morphological analysis}


For ultrastructural studies of $O$. balibaloi and $O$. lobularis, sponge fragments $\left(8-10 \mathrm{~mm}^{3}\right.$, about 15-20 fragments for each species) were fixed according to the following protocol: 1) the buffer used in all fixatives was prepared by mixing cacodylate $0.2 \mathrm{M}$ with seawater (1:2); 2) prefixation was carried out for $3 \mathrm{~min}$ by the addition of $1 \mathrm{ml}$ of osmium tetroxide $1 \%$ to $3 \mathrm{ml}$ of seawater with a sponge fragment; 3 ) then, $4 \mathrm{ml}$ of glutaraldehyde $4 \%$ were added, and the sponge fragment was maintained in this mixture for $15 \mathrm{~min}$, on ice and in darkness; 4) then the fixative mixture was replaced by $4 \mathrm{ml}$ of glutaraldehyde $2 \%$ for $1 \mathrm{~h}$ on ice; 5) samples were then rinsed twice in the buffer and post-fixed with osmium tetroxide $1 \%$ for $1 \mathrm{~h}$. Finally, the samples were washed twice in the buffer for $10 \mathrm{~min}$, dehydrated through graded concentrations of ethanol and embedded in Epon Araldite. After polymerization, the resin blocks containing the sponge fragments were trimmed with a Leica EM UC6 ultramicrotome using a glass knife and Leica UCT ultramicrotome equipped with a Drukkert $45^{\circ}$ diamond knife. The ultrathin sections were stained with $2 \%$ uranyl acetate in $70 \%$ ethanol and Reynolds' lead citrate, and then observed using a JEM 1400 transmission electron microscope (TEM) equipped with an Olympus Veleta digital camera, and a Zeiss-1000 TEM. In total, about 50-70 choanocytes of each species were analized during this study. For most of them, serial longitudinal or transverse sections were obtained.

For more basic TEM observations of choanocytes including the shape and position of the nucleus, samples of O. tuberculata, O. viridis, O. microlobata, O. carmela, O. pearsei, O. malakhovi, $O$. kamchatkensis, O. rubra and Pseudocorticium jarrei were fixed in glutaraldehyde $2.5 \%$, prepared with cacodylate buffer $0.2 \mathrm{M}$ and filtered seawater, during $2 \mathrm{~h}$, and post-fixed in $\mathrm{OsO}_{4} 2 \%$ in seawater for $2 \mathrm{~h}$ at room temperature. After fixation, samples were successively washed in $0.2 \mathrm{M}$ cacodylate buffer and distilled water, and finally dehydrated with a graded series of ethanol and embedded in Epon Araldite. Ultrathin sections were cut and stained in the same way as described above. Oscarella imperialis Muricy, Boury-Esnault, Bézac, \& Vacelet, 1996, O. filipoi Pérez, Ruiz, 2018, and O. zoranja Pérez, Ruiz, 2018 were analyzed on the basis of original descriptions.

\section{Phylogenetic reconstruction}

To assess the possible phylogenetic value of the studied morphological characters we conducted a phylogenetic analysis, based on molecular data from previously published papers (Gazave et al., 2013; Ereskovsky et al., 2017; Pérez, \& Ruiz, 2018). For most oscarellid diversity, the two markers sequenced most often, were the nucear 28S rRNA gene (28S) and 18S rRNA gene (18S) and it was 
shown that phylogenetic reconstructions, based on these markers, are compatible to those from mtDNA (Gazave et al., 2013; Ereskovsky et al., 2017). However, for two species included in the morphological analysis (O. filipoi and $O$. zoranja), only mitochondrial cytochrome c oxidase subunit 1 (COI) sequences (I3-M11 fragment) (Pérez, \& Ruiz, 2018) were used. Therefore, to improve the resolution of phylogenetic reconstructions, the final dataset included all three loci, even if only COI was available for some species. In the case of $O$. pearsei, a preliminary analysis showed that all GenBank 28S and 18S sequences under its species name (acc. numbers EF654526, EF654519, KY513286) are identical to corresponding $O$. carmela sequences. As a result, $O$. pearsei grouped together with $O$. carmela, contradicting phylogenetic hypotheses of Ereskovsky et al. (2017). Therefore, to avoid possible misidentification and wrongly interpreted results, for $O$. pearse $i$ only the COI sequence was included in the final dataset. Species from the family Plakinidae and Leucaltis clathria were chosen as outgroups (Ereskovsky et al., 2017). GenBank accession numbers for studied specimens are given in Table 1. Both alignments and original tree files have been deposited in Zenodo (https://zenodo.org/record/3706996\#.XmoBq-oueUl).

Sequences were aligned with MUSCLE (Edgar, 2004) in MEGA7 (Kumar, Stecher, \& Tamura, 2016). Indel-rich regions of the $28 \mathrm{~S}$ and $18 \mathrm{~S}$ markers were identified and removed with Gblocks (Talavera and Castresana, 2007). We determined blocks using a less stringent selection by allowing gap positions within the final blocks and less strict flank positions. The length of resulting alignments was of $492 \mathrm{bp}$ for COI, $1630 \mathrm{bp}$ for $18 \mathrm{~S}$ and $1120 \mathrm{bp}$ for 28S, and after using Gblocks it consisted of $492 \mathrm{bp}$ for COI, $1582 \mathrm{bp}$ for $18 \mathrm{~S}$ and $979 \mathrm{bp}$ for 28S. Since only publicly available sequences were used, and single-gene trees for each marker have been already published (Gazave et al., 2013; Ereskovsky et al., 2017; Pérez, \& Ruiz, 2018), only an analysis based on concatenated sequences was conducted. Sequences were concatenated by a simple biopython script (Chaban, Ekimova, Schepetov, \& Chernyshev, 2019). The best-fitting nucleotide evolution model was tested in the MEGA7 toolkit based on the Bayesian information criterion (BIC) for each partition. The best-fitting model for COI partition was $\mathrm{HKY}+\mathrm{G}$, for $28 \mathrm{~S}$ partition $-\mathrm{GTR}+\mathrm{G}$, and for $18 \mathrm{~S}$ partition the best model was $\mathrm{K} 2+\mathrm{G}$. Phylogenetic reconstructions were performed by applying evolutionary models for partitions separately. The Bayesian estimation of posterior probability was performed in MrBayes 3.2 (Ronquist, \& Huelsenbeck, 2003). Markov chains were sampled at intervals of 500 generations. The analysis was started with random starting trees and $3 \times 10^{6}$ generations. Maximum Likelihood-based phylogeny inference was performed in HPC-PTHREADS-AVX version of RAxML (Stamatakis, 
2014) with ultrafast bootstrapping (UFBoot approximation approach) (Minh, Nguyen, \& von Haeseler, 2013) in 1000 pseudoreplicates under the GTRCAT approximation of nucleotide evolution. Bootstrap values were placed on the best tree found, with SumTrees 3.3.1 from DendroPy Phylogenetic Computing Library V 3.12.0 (Sukumaran, \& Holder, 2010). Final phylogenetic tree images were edited in FigTree 1.4.0. and further colored using Adobe Illustrator CC2015.

\section{Results}

\section{Kinetid structure of Oscarella lobularis choanocytes}

Choanocytes of $O$. lobularis are elongated in an apical-basal direction (Fig. 2 A). The flagellum has a typical eukaryotic axoneme $(9+2)$. After fixation, the flagellum often became squeezed at its base (Figs. 2A; 3B). Central microtubules start approximately 120-200 $\mathrm{nm}$ above the level of the cell surface (Figs. 3C; 4J); therefore, the transition zone (area between the proximal ends of the central microtubules and kinetosome) can be classified as moderately long. At high magnification we distinguished latticed bodies in the transition zone (Fig. 4 I). Slightly more distal from these bodies, the flagellum is filled with electron-dense material (Figs. $3 \mathrm{~B} ; 4 \mathrm{H}$; I). The kinetosome consists of nine microtubular triplets (Figs. 3 B, C; 4 C-E). An axial granule (the dense body usually found in sponge choanocytes in this location (Pozdnyakov and Karpov, 2015; Pozdnyakov et al., 2017)) is attached by filaments to microtubules in the distal part of the kinetosome (Figs. 3 C; 4 B, F; I-K). In longitudinal sections, the axial granule is revealed as a three-layered structure: two dense plates separated by an electron translucent layer (Figs. $3 \mathrm{C} ; 5 \mathrm{~J}$ ).

Nine thick transitional fibrils, nearly $130 \mathrm{~nm}$ long, radiate from the distal end of the kinetosome (Figs. $3 \mathrm{H}$; 4 B, C, F), each of them has a shape of an elongated triangle with the apex connecting to the plasma membrane (Fig. 4 C, F; K). Small electron-dense bodies mark the place where the transitional fibrils connect to the cell membrane (Figs. $3 \mathrm{E} ; 4 \mathrm{C}-\mathrm{F}$ ).

The basal foot is 150-170 nm long, has a wide base, and is located on the lateral side of the distal part of the kinetosome (Figs. $3 \mathrm{E} ; 4 \mathrm{D}, \mathrm{E}$ ). It consists of two or three stalks attached to the kinetosome and a spherical head (Fig. 4 D), which serves as a microtubule organizing center (MTOC). Numerous microtubules radiate from the head in different directions (Figs. 3 D; 4 D-E). Some of them reach the plasma membrane, whereas others pass towards the nucleus or along the lateral sides of the 
kinetosome. We also observed lateral microtubules starting directly from the kinetosome surface, but we did not find pronounced additional MTOCs here (Fig. 4 D, E).

A non-flagellar centriole is present in choanocytes of $O$. lobularis (Fig. 3 A-J). It is located in a more basal position than the basal foot (Fig. 3 D, E), at a short distance from the kinetosomal edge (Fig. $3 \mathrm{~B}, \mathrm{G}, \mathrm{H}$ ). The longitudinal axis of the centriole is perpendicular to the basal foot, as well as to the kinetosome (Fig. 3 A-E). A fibrillar bridge connects the kinetosome and centriole (Fig. 3 C, D). A thick non-striated fibrillar root of arcuate shape projects from the centriole in a lateral direction (Fig. 3 G-I).

The kinetosome of the $O$. lobularis choanocyte has no fibrillar root. The nucleus occupies a basal position in the cell and is separated from the kinetosome by almost the entire cytoplasm (Fig. 2 A). Additionally, the cisternae of the Golgi apparatus and large vacuoles filled with fibrillar material are located between the kinetosome and the nucleus (Fig. 4 L). Therefore, the nucleus is disconnected to the flagellar apparatus. A schematic drawing (Fig. 5) summarizes the structure of choanocyte kinetid in $O$. lobularis.

\section{Kinetid structure of Oscarella balibaloi choanocytes}

Choanocytes of $O$. balibaloi have a flagellum with a typical axoneme $(9+2)$. Usually, it becomes squeezed near its base after fixation (Figs. 2 B; 6 F, G). The flagellar transition zone is moderately long (Figs. 2 A; 6 F).

The kinetosome consists of nine microtubular triplets (Figs. 6 D-F, I; 7 A-E). It contains an axial granule connected by thin filaments with the inner surface of the kinetosome (Fig. 6 I). The axial granule is elongated in an apical-basal direction and its shape is irregular. Transitional fibers project radially from the distal end of the kinetosome forming a star-like structure (Figs. $6 \mathrm{~F} ; 7 \mathrm{~A}$ ). The kinetosome surface bears a triangle-shaped basal foot with lateral microtubules (Figs. 6 D-F; K; 7 BC). We did not find additional MTOCs, but observed microtubules starting directly from the kinetosome (Fig. 7 C).

The centriole of $O$. balibaloi is located near the kinetosome, in the same position as in the choanocytes of $O$. lobularis. The fibrillar bridge connects the kinetosome with the centriole (Figs. 6 D, E; 7 E). It merges with the non-striated fibrillar lateral root starting from the centriole (Fig. $6 \mathrm{~J}$ ). The choanocyte of $O$. balibaloi has an apical nucleus, and the broad and short (about $120 \mathrm{~nm}$ length) non-striated fibrillar root projecting from the proximal end of the kinetosome attaches to the nuclear 
surface (Figs. 2 B; 6 C, D, I, J). Cross sections reveal the fibrillar ring connecting the kinetosome to the conical nuclear projection (Fig. 7 F). The Golgi apparatus is located slightly more basally than the centriole, being situated aside the flagellar apparatus and nucleus (Fig. 6 A, B). A schematic drawing illustrating the choanocyte kinetid of $O$. balibaloi is shown in figure 8.

\section{Kinetid structure of choanocytes in other Oscarellidae species}

The analysis of longitudinal sections of different Oscarella species reveals that the choanocyte nucleus is located in a basal position without any connection to the kinetosome in O. rubra (Fig. 9 A), O. bergenensis (Fig. 9 B), O. tuberculata (Fig. 9 C), O. carmela (Fig. 9 D), O. viridis (Fig. 9 E), O. microlobata (Fig. 9 F), O. malakhovi (Fig. 9 G). As in O. lobularis, the Golgi apparatus and large vacuoles are located between the kinetosome and the nucleus. Additionally, the kinetosomes of these species do not possess fibrillar roots. Therefore, the general scheme of their kinetid structure corresponds to the flagellar apparatus of $O$. lobularis.

In the choanocytes of $O$. nicolae (Fig. $9 \mathrm{H}$ ), O. kamchatkensis (Fig. $9 \mathrm{I}$ ) and $O$. pearsei (Fig. $9 \mathrm{~J}$ ), the nucleus occupies an apical position and connects to the kinetosome by fibrillar roots. Thus, the choanocytes of these three species have a flagellar apparatus similar to O. balibaloi. Moreover, the same scheme of the kinetid structure was also found in the choanocytes of Pseudocorticium jarrei, the only species of Oscarellidae that does not belong to the genus Oscarella (Fig. 9 K).

\section{Phylogenetic tree of the family Oscarellidae}

The sequence alignment of concatenated 28S, 18S, and COI markers included a total of 3264 positions before GBlocks applied, and 3053 position after using GBlocks. The topology of the trees resulting from the Bayesian Inference (BI; Fig. 10) and the Maximum Likelihood analysis (ML) of the concatenated alignments were largely congruent in both topology and nodes support. The BI tree, however, contained more polytomies corresponding to poorly supported nodes in the ML tree. No conflict in supported nodes in the single-gene trees (28S, 18S, and COI; Gazave et al., 2013; Ereskovsky et al., 2017; Pérez, \& Ruiz, 2018) and the trees found in analyses of the concatenated sequences (both pre- and post-GBlocks) was identified. The family Oscarellidae was monophyletic and highly supported (PP (posterior probability from the Bayesian Inference) $=1$; ML (bootstrap values from the Maximum Likelihood) =100). The genus Oscarella was recovered paraphyletic due to Pseudocorticium jarrei nested within it $(\mathrm{PP}=1 ; \mathrm{ML}=99)$. Within the Oscarella + 
Pseudocorticium clade there are two highly supported large species groups: the first one comprises Oscarella lobularis, O. bergenensis, O. lobularis, O. rubra, O. carmela, O. malakhovi, O. viridis, $O$. filipoi and $O$. zoranja $(\mathrm{PP}=1 ; \mathrm{ML}=100)$. The second group includes O. balibaloi, O. pearsei, $O$. kamchatkensis, O. nicolae and Pseudocorticium jarrei $(\mathrm{PP}=1 ; \mathrm{ML}=99)$. Oscarella microlobata represents a singleton that is recovered as sister to the first group (forming a common group with them), however the node support is moderate or low in this case $(\mathrm{PP}=0.97 ; \mathrm{ML}=36)$. Within two mentioned groups of species some supported clades of closely related species can be found: $O$. bergenensis is sister to $O$. tuberculata $(\mathrm{PP}=1 ; \mathrm{ML}=97)$ and both form a single clade together with O. lobularis and $O$. rubra $(\mathrm{PP}=1 ; \mathrm{ML}=98) ; O$. carmela is sister to O. malakhovi $(\mathrm{PP}=1 ; \mathrm{ML}=$ $100)$ and $O$. balibaloi is sister to $O$. nicolae $(\mathrm{PP}=1 ; \mathrm{ML}=91)$. Recovered relationships between other species received moderate or low support.

\section{Discussion}

The choanocyte kinetids of Oscarella lobularis and $O$. balibaloi closely resemble the kinetids of previously studied sponge species (Pozdnyakov, \& Karpov, 2013, 2016a, 2016b; Pozdnyakov et al., 2017, 2018). However, two features found in Oscarella choanocyte kinetids have not been found in the choanocyte kinetids of other sponges: these are the single microtubule organizing center (MTOC $=$ basal foot) on the kinetosome without any additional ones, and a centriole with its own lateral fibrillar root. The basal or apical position of the nucleus in choanocytes of $O$. lobularis and $O$. balibaloi correlates well with corresponding absence or presence of a nuclear fibrillar root in their kinetosomes (Figs. 5; 8). Based on these traits, all investigated species of the genus Oscarella can be divided into two groups.

The "lobularis-group" (Figs. 2 A; 9 A-G) includes O. lobularis, O. tuberculata, O. bergenensis, $O$. viridis, O. rubra, O. malakhovi, O. microlobata, O. carmela, O. filipoi and O. zoranja. Their choanocyte nuclei are located in a basal position without any connection to the kinetosome. The Golgi apparatus is located between the kinetid and a vacuole containing fibrillar material. The kinetosomes of choanocytes in these species do not possess fibrillar roots.

The "balibaloi-group” (Figs. 2 B; 9 H-K) includes $O$. balibaloi, O. nicolae, O. kamchatkensis, $O$. pearsei and Pseudocorticium jarrei. Their choanocytes have apical nuclei connected to the kinetosomes with fibrillar roots. 
The two groups described in our phylogenetic analysis are strongly congruent with recent comprehensive studies based on multi-locus analysis (Gazave et al., 2013), and with additional studies that grouped $O$. filipoi and $O$. zoranja with the members of "lobularis-group", and $O$. pearsei with the species of the "balibaloi-group" (Ereskovsky et al., 2017; Pérez, \& Ruiz, 2018). The position of $O$. microlobata was conflicting in different phylogenies. It fell into the same group either with $O$. lobularis (Gazave et al., 2013, Gloeckner, Hentschel, Ereskovsky, \& Schmitt, 2012), or with $O$. balibaloi (Ivanišević et al., 2011; Ereskovsky et al., 2017; Perez, \& Ruiz 2018 ), or was recovered as sister to all other oscarellids (Gazave et al., 2010; Ereskovsky et al., 2017). Our results further support the close relationships of this species with the remaining members of the "lobularis-group", and thus confirm the monophyly of this group as a whole. The unstable position of $O$. microlobata could be a result of low substitution rates and a resulting unclear phylogenetic signal in the case of single-gene analyses.

The representatives of Plakinidae, another family of Homoscleromorpha, possess a choanocyte kinetid structure similar to that found in the "balibaloi-group" (Riesgo, Maldonado, \& Durfort, 2007). Therefore, we can assume that the choanocyte kinetid of the "balibaloi-group" retained the plesiomorphic condition of homoscleromorph kinetid, in contrast to the ones found in the "lobularisgroup" where the kinetid structure is apomorphic.

There is an additional cytological trait supporting the proposed subdivision of Oscarellidae into two clades: particular mesohylar spherulous cells containing paracrystalline inclusions are characteristic of all Oscarella species in the "balibaloi-group" (Muricy, Boury-Esnault, Bézac, \& Vacelet, 1996; Pérez et al., 2011; Ereskovsky, Sanamyan, Vishnyakov, 2009; Ereskovsky et al., 2017; Gazave et al., 2013). These cells are ovoid, rarely spherical, with an anucleolated nucleus. Their paracrystalline inclusions are usually ovoid or cylindrical elements consisting of fibrils arranged in a cross striated pattern. This trait is also known for Pseudocorticium jarrei. Interestingly, it has never been observed in neither Plakinidae, nor in species of the "lobularis-group" with the exception of $O$. microlobata. This latter species possesses superficially similar cells with inclusions, but in comparison to the "balibaloi-group", their paracrystalline elements are less numerous and dispersed within the dense matrix of the cell spherules. According to our suggestion, the "balibaloigroup" should also include Oscarella imperialis, because according to its original description this species has an apical choanocyte nucleus and typical spherulous cells with paracrystalline inclusions (Muricy et al., 1996). 
The documented distribution of cells with paracrystalline inclusions within the family Oscarellidae corresponds to the phylogenetic relationships of the two species groups. This cell type might be an ancestral feature for Oscarellidae, since it is not found in any other sponges except of species in the "balibaloi-group" and O. microlobata. It was retained in the "balibaloi-group" while in the "lobularis-group" it could be reduced, with $O$. microlobata demonstrating partial reduction of this character.

The two groups recovered in our molecular phylogenetic analysis strongly support our morphological results and suggest a phylogenetic and, probably, taxonomic importance of the choanocyte kinetid structure within the family Oscarellidae. According to our findings, the kinetid structure of choanocytes seems to be a valid diagnostic trait distinguishing the two main clades of Oscarellidae, and we propose to include this cytological character in future species descriptions.

Our results highlight the need to revise the family Oscarellidae and at the current state of knowledge imply assignment of the "balibaloi-group" to the genus Pseudocorticium. However, missing genetic and cytological information on few other Oscarella species calls for additional research and does not allow us to propose a formal taxonomic redefinition of the family.

\section{Acknowledgments}

The research was supported by the Russian Foundation for Basic Research (RFBR), project number 18-04-01314. IP was supported by the ZIN RAS research project AAAA-A19119031200042-9. The work of AS was conducted under the Institute of Developmental Biology National Basic Research Program 0088-2019-0005 and Russian Foundation for Basic Research (RFBR), project number 18-04-01213. SK was supported by the ZIN RAS research project AAAAA19-119020690109-2 and the program of the RAS Presidium "Evolution of the organic world. The role and significance of planetary processes". We thank Research Resource Center for Microscopy at Zoological Institute of Russian Academy of Sciences and Research Resource Center for Molecular and Cell Technologies (RRC MCT) at St. Petersburg State University for access to the EM facilities. We are also grateful to Alexandre Altié of Service Commun de Microscopie Électronique et Photographie Faculté de Médecine La Timone, Aix-Marseille Université, thanks to Sandrine Chenesseau from the staff of the Common Service of morphology in the Mediterranean Institute of Marine and Terrestrial Biodiversity and Ecology (IMBE) Marseille - for assistance with electron 
microscopy studies, Daria Tokina for technical support and B.S.C. Leadbeater for correction of the English. 


\section{References}

Andersen, R. A., Barr, D. J. S., Lynn, D. N., Melkonian, M., Moestrup, Ø., \& Sleigh, M. A. (1991). Terminology and nomenclature of the cytoskeletal elements associated with the flagellar/ciliary apparatus in protists. Protoplasma, 164, 1-8.

Baldauf, S. L. (1999). A search for the origins of animals and fungi, comparing and combining data. American Naturalist, 154, 178-188. https://doi.org/10.1086/303292

Barr, D. J. S. (1981). The phylogenetic and taxonomic implications of flagellar rootlet morphology among zoosporic fungi. BioSystems, 14, 359-370. https://doi.org/10.1016/03032647(81)90042-3

Bidder, G. (1898). The skeleton and classification of calcareous sponge. Proceedings of the Royal Society of London, 64, 61-76. https://doi.org/10.1098/rspl.1898.0070

Boury-Esnault, N., Lavrov, D., Ruiz, C., \& Pérez, T. (2013). The integrative taxonomic approach applied to Porifera: a case study of the Homoscleromorpha. Integrative and Comparative Biology, 53, 416-427. https://doi.org/10.1093/icb/ict042

Boury-Esnault, N., Muricy, G., Gallissian, M.-F., \& Vacelet, J. (1995). Sponges without skeleton: A new Mediterranean genus of Homoscleromorpha (Porifera, Demospongiae). Ophelia, 43(1), 25-43. https://doi.org/10.1080/00785326.1995.10430575

Cavalier-Smith, T. (2000). Flagellate megaevolution: the basis for eukaryote diversification. In: J. Green, \& B. Leadbeater (Eds.), The Flagellates (pp. 361-390). London: Taylor and Francis.

Cavalier-Smith, T. (2013). Early evolution of eukaryote feeding modes, cell structural diversity, and classification of the protozoan phyla Loukozoa, Sulcozoa, and Choanozoa. European Journal of Protistology, 49, 115-178. https://doi.org/10.1016/j.ejop.2012.06.001

Chaban, E. M., Ekimova, I. A., Schepetov, D. M., \& Chernyshev, A. V. (2019). Meloscaphander grandis (Heterobranchia: Cephalaspidea), a deep-water species from the North Pacific: Redescription and taxonomic remarks. Zootaxa, 4646(2), 385-400. https://doi.org/10.11646/zootaxa.4646.2.12

Dewel, R. A., Connell, M. U., \& Dewel W. C. (2003). Bridging Morphological Transitions to the Metazoa. Integrative and Comparative Biology, 43, 28-46. https://doi.org/10.1093/icb/43.1.28

Edgar, R.C. (2004). MUSCLE: multiple sequence alignment with high accuracy and high throughput. Nucleic acids research. 32(5), 1792-1797. https://doi.org/10.1093/nar/gkh340 
Ereskovsky, A. V., Richter, D. J., Lavrov, D. V., Schippers, K. J., Nichols, S. A., \& Mans, B. J. (2017). Transcriptome sequencing and delimitation of sympatric Oscarella species (O. carmela and O. pearsei sp. nov) from California, USA, PLoS ONE, 12, e0183002.

https://doi.org/10.1371/journal.pone.0183002

Ereskovsky, A. V., Sanamyan, K., \& Vishnyakov, A. E. (2009). A new species of the genus Oscarella (Porifera: Homosclerophorida: Plakinidae) from the North-West Pacific. Cahiers de Biologie Marine, 50, 369-381. https://doi.org/10.21411/cbm.a.91c6a28c

Gazave, E., Lapébie, P., Ereskovsky, A. V., Vacelet, J., Renard, E., Cárdenas, P., \& Borchiellini, C. (2012). No longer Demospongiae: Homoscleromorpha formal nomination as a fourth class of Porifera. Hydrobiologia, 687, 3-10. https://doi.org/10.1007/s10750-011-0842-X

Gazave, E., Lapébie, P., Renard, E., Vacelet, J., Rocher, C., Ereskovsky, A. V., Lavrov, D. V., \& Borchiellini, C. (2010). Molecular phylogeny restores the supra-generic subdivision of Homoscleromorph sponges (Porifera, Homoscleromorpha). PLoS ONE, 5, e14290. https://doi.org/10.1371/journal.pone.0014290

Gazave, E., Lavrov, D. V., Cabrol, J., Renard, E., Rocher, C., Vacelet, J., Adamska, M., Borchiellini, C., Ereskovsky, A. V., \& Colgan, D. J. (2013). Systematics and Molecular Phylogeny of the Family Oscarellidae (Homoscleromorpha) with Description of two new Oscarella Species. PLoS ONE, 8, e63976. https://doi.org/10.1371/journal.pone.0063976

Gloeckner, V., Hentschel, U., Ereskovsky, A. V., \& Schmitt, S. (2013). Unique and speciesspecific microbial communities in Oscarella lobularis and other Mediterranean Oscarella species (Porifera: Homoscleromorpha). Marine Biology, 160(4), 781-791. https://doi.org/10.1007/s00227012-2133-0

Hanitsch, R. (1890). Third Report on the Porifera of the L.M.B.C.District. Proceedings and Transactions of the Liverpool Biological Society, 4, 192-238, pls X-XV.

Ivanisevic, J., Thomas, O. P., Pedel, L., Pénez, N. Ereskovsky, A. V., Culioli, G., \& Pérez, T. (2011). Biochemical Trade-Offs: Evidence for Ecologically Linked Secondary Metabolism of the Sponge Oscarella balibaloi. PLoS One, 6, e28059. https://doi.org/10.1371/journal.pone.0028059

Karpov, S. A. (1988). The structure of flagellar rootlets in the moving cells of algae, fungi and colourless flagellates. Tsitologia, 30(4), 371-389 (in Russian).

Karpov, S. A. (2000). Flagellate phylogeny: ultrastructural approach. In: J. Green, \& B. Leadbeater (Eds.), The Flagellates (pp. 336-360). London: Taylor and Francis. 
Karpov, S. A. (2016). Flagellar apparatus structure of choanoflagellates. Cilia, 5, 11. https://doi.org/10.1186/s13630-016-0033-5

Kumar, S., Stecher, G., \& Tamura, K. (2016). MEGA7: molecular evolutionary genetics analysis version 7.0 for bigger datasets. Molecular biology and evolution. 33(7), 1870-1874. https://doi.org/10.1093/molbev/msw054

Letcher, P. M., Powell, M. J., Chambers, J. G., Longcore, J. E., Churchill, P. F., \& Harris, P. M. (2005). Ultrastructural and molecular delineation of the Chytridiaceae (Chytridiales). Canadian Journal of Botany, 82, 1561- 1573. https://doi.org/10.1139/b05-115

Manuel, M. (2006). Phylogeny and evolution of calcareous sponges. Canadian Journal of Zoology, 84, 225-241. https://doi.org/10.1139/z06-005

Manuel, M., Borchiellini, C., Alivon, E., Le Parco, Y., Vacelet, J., \& Boury-Esnault, N. (2003). Phylogeny and evolution of calcareous sponges: Monophyly of Calcinea and Calcaronea, high level of morphological homoplasy, and the primitive nature of axial symmetry. Systematic Biology, 52, 311-333. https://doi.org/10.1080/10635150390196966

Melkonian, M. (1982). Structural and evolutionary aspects of the flagellar apparatus in green algae and land plants. Taxon, 31, 255-265. https://doi.org/10.2307/1219989

Minchin, E. A. (1896). Note on the larva and the postlarval development of Leucosolenia variabilis H. sp., with remarks on the development of other Asconidae. Proceedings of the Royal Society of London. 60, 43-52. https://doi.org/10.1098/rspl.1896.0013

Minh, B.Q., Nguyen, M.A.T., \& von Haeseler, A., 2013. Ultrafast approximation for phylogenetic bootstrap. Molecular biology and evolution. 30(5), 1188-1195. https://doi.org/10.1093/molbev/mst024

Moestrup, Ø. (1982). Flagellar structure in algae: a review, with new observations particularly on the Chrysophyceae, Phaeophyceae (Fucophyceae), Euglenophyceae, and Reckertia. Phycologia, 21, 427-528. https://doi.org/10.2216/i0031-8884-21-4-427.1

Moestrup, Ø. (2000). The flagellar cytoskeleton: introduction of general terminology for microtubular flagellar roots in protists. In: J. Green, \& B. Leadbeater (Eds.), The Flagellates (pp. 6994). London: Taylor and Francis.

Muricy, G., Boury-Esnault, N., Bézac, C., \& Vacelet, J. (1996). Cytological evidence for cryptic speciation in Mediterranean Oscarella species (Porifera, Homoscleromorpha). Canadian Journal of Zoology, 74, 881-896. https://doi.org/10.1139/z96-102 
O'Kelly, C. J., \& Floyd, G. L. (1983). Flagellar apparatus absolute orientations and the phylogeny of the green algae. BioSystems, 16, 227-251. https://doi.org/10.1016/0303-2647(83)90007-2

Pérez, T., \& Ruiz, C. (2018). Description of the first Caribbean Oscarellidae (Porifera: Homoscleromorpha). Zootaxa, 4369, 501-514. http://dx.doi.org/10.11646/zootaxa.4369.4.3

Pérez, T., Ivanisevic, J., Dubois, M., Pede, L., Thomas, O. P., Tokina, D., \& Ereskovsky, A. V. (2011). Oscarella balibaloi, a new sponge species (Homoscleromorpha: Plakinidae) from the Western Mediterranean Sea: cytological description, reproductive cycle and ecology. Marine Ecology, 32, 174-187. https://doi.org/10.1111/j.1439-0485.2011.00435.x

Pozdnyakov, I. R., \& Karpov, S. A. (2013). Flagellar apparatus structure of choanocyte in Sycon sp. and its significance for phylogeny of Porifera. Zoomorphology, 132, 351-357. https://doi.org/10.1007/s00435-013-0193-4

Pozdnyakov, I. R., \& Karpov, S. A. (2016a). Structure of choanocyte's kinetid in sponge Haliclona sp. (Demospongiae, Haplosclerida) and its implication for taxonomy and phylogeny of Demospongiae. Biology Bulletin of Russian Academy of Science, 43, 595-601. https://doi.org/10.1134/S1062359016070153

Pozdnyakov, I. R., \& Karpov, S. A. (2016b). Kinetid structure in choanocytes of sponges (Heteroscleromorpha), toward the ancestral kinetid of Demospongiae. Journal of Morphology, 277, 925-934. https://doi.org/10.1002/jmor.20546

Pozdnyakov, I. R., Sokolova, A. M., Ereskovsky, A. V., \& Karpov, S. A. (2017). Kinetid structure of choanoflagellates and choanocytes of sponges does not support their close relationship. Protistology, 11, 248-264. https://doi.org/10.21685/1680-0826-2017-11-4-6

Pozdnyakov, I. R., Sokolova, A. M., Ereskovsky, A. V., \& Karpov, S.A. (2018). Kinetid structure in sponge choanocytes of Spongillida in the light of evolutionary relationships within Demospongiae. Zoological Journal of the Linnean Society, 184, 255-272. https://doi.org/10.1093/zoolinnean/zlx 109

Riesgo, A., Maldonado, M., \& Durfort, M. (2007). Dynamics of gametogenesis, embryogenesis, and larval release in a Mediterranean homosclerophorid demosponge. Marine and Freshwater Research, 58, 398-417.

Ronquist, F., \& Huelsenbeck, J.P. (2003). MrBayes 3: Bayesian phylogenetic inference under mixed models. Bioinformatics. 19(12), 1572-1574. https://doi.org/10.1093/bioinformatics/btg180

Ruiz, C., Muricy, G., Lage, A., Domingos, C., Chenesseau, S., \& Pérez, T. (2017). Descriptions of new sponge species and genus, including aspiculate Plakinidae, overturn the Homoscleromorpha 
classification. Zoological Journal of the Linnean Society, 179, 707-724.

https://doi.org/10.1111/zoj.12480

Stamatakis, A. (2014). RAxML version 8: a tool for phylogenetic analysis and post-analysis of large phylogenies. Bioinformatics. 30(9), 1312-1313. https://doi.org/10.1093/bioinformatics/btu033.

Sukumaran, J., \& Holder, M.T. (2010). DendroPy: a Python library for phylogenetic computing. Bioinformatics. 26(12), 1569-1571. https://doi.org/10.1093/bioinformatics/btq228.

Talavera, G., \& Castresana, J. (2007). Improvement of phylogenies after removing divergent and ambiguously aligned blocks from protein sequence alignments. Systematic biology. 56(4), 564-577. https://doi.org/10.1080/10635150701472164

Van Soest, R. W. M., Boury-Esnault, N., Hooper, J. N. A., Rützler, K., de Voogd, N.J., Alvarez, B., ... Downey, R. (2019). World Porifera Database. Aplysilla rosea (Barrois, 1876). Accessed through: World Register of Marine Species at: id=132296 on 2019-05-30

Yubuki N., \& Leander, B.S. (2013). Evolution of Microtubule Organizing Centers Across the Tree of Eukaryotes. The Plant Journal. 75, 230-244. 


\section{Figures and legends}

Fig. 1. General scheme of structures of the choanocyte flagellar apparatus.

A) Schematic overview of choanocyte. Area marked by red rectangle is magnified in B. B) The flagellar apparatus (= kinetid) magnified (see area marked by red rectangle in A).

Abbreviations: I - flagellum; II - basal intracellular part; III - transition zone.

bf - basal foot; c - centriole; $\mathrm{cmt} \mathrm{-} \mathrm{central} \mathrm{microtubules;} \mathrm{fl} \mathrm{-} \mathrm{flagellum;} \mathrm{fr} \mathrm{-} \mathrm{fibrillar} \mathrm{root;} \mathrm{Ga}$ Golgi apparatus; $\mathrm{k}$ - kinetosome; lmt - lateral microtubules; mv - microvilli; $\mathrm{n}$ - nucleus; pdm peripherical duplets of microtubules; pm - plasma membrane; $\mathrm{tf}$ - transition fibril.

Fig. 2. Overviews of choanocytes of Oscarella lobularis (A) and O. balibaloi (B) in longitudinal sections.

Abbreviations: fl - flagellum; $\mathrm{k}$ - kinetosome; $\mathrm{n}$ - nucleus; vfm - vacuole with fibrillar material.

Fig. 3. Transmission electron micrographs of the flagellar apparatus in Oscarella lobularis.

A-E) series of consecutive longitudinal sections through the kinetosome; F) section through the longitudinal axis of the kinetosome of another choanocyte; G-I) series of consecutive sections through the kinetosome of another choanocyte.

Abbreviations: ag - axial granule; bf - basal foot; $\mathrm{c}$ - centriole; ecm - ends of central microtubules; edm - electron-dense material; fb - fibrillar bridge between centriole and kinetosome; $\mathrm{fr}$ - fibrillar root; Ga - Golgi apparatus; k - kinetosome; lfr - lateral fibrillar root; lmt - lateral microtubules; $\mathrm{n}$ - nucleus; $\mathrm{pc}$ - places of connection (of transition fibers to the plasmalemma); $\mathrm{tf}-$ transition fiber.

Fig. 4. Transmission electron micrographs of the flagellar apparatus in Oscarella lobularis.

A-E) series of consecutive transverse sections through the transition zone and kinetosome from distal to proximal end (view from inside the cell); F-H) series of consecutive transverse sections through the transition zone of another choanocyte from proximal to distal direction (view from outside the cell); I, J) longitudinal sections through the transition zone and axial granule of different choanocytes; K) transverse section through the axial granule of another choanocyte; L) longitudinal section through the flagellar apparatus of one more choanocyte. 
Abbreviations: ag - axial granule; bf - basal foot; c - centriole; ecm - ends of central microtubules; edm - electron-dense material; Ga - Golgi apparatus; hbf - head of basal foot; $\mathrm{k}$ kinetosome; lmt - lateral microtubules; lb - lattice body; pd - peripheral doublet of microtubules; sbf - stem of basal foot; $\mathrm{tf}$ - transition fiber; $\mathrm{tz}$ - transition zone; vfm - vacuole with fibrillar material.

Fig. 5. Schematic representation of Oscarella lobularis kinetid in lateral view.

Abbreviations: ag - axial granule; bf - basal foot; c - centriole; edm - electron-dense material; $\mathrm{fb}$ - fibrillar bridge between centriole and kinetosome; fl - flagellum; Ga - Golgi apparatus; k kinetosome; lfr - lateral fibrillar root; lmt - lateral microtubules; $\mathrm{n}$ - nucleus; $\mathrm{lb}$ - lattice body; tf transition fiber; vfm - vacuole with fibrillar material.

Fig. 6. Transmission electron micrographs of the flagellar apparatus of Oscarella balibaloi.

A-H) series of consecutive longitudinal sections through the kinetosome; F) section through the longitudinal axis of the kinetosome of another choanocyte; J) lateral fibrillar root; K) structure of basal foot; L) pattern of lateral microtubules originating in the basal foot ( $\mathrm{J}, \mathrm{K}, \mathrm{L}$ - different choanocytes).

Abbreviations: ag - axial granule; bf - basal foot; $\mathrm{c}$ - centriole; fb - fibrillar bridge between centriole and kinetosome; fr - fibrillar root; fm - fibrillar material; Ga - Golgi apparatus; k kinetosome; lfr - lateral fibrillar root; lmt - lateral microtubules; $1 \mathrm{mt}(\mathrm{lv})$ - lateral microtubules (longitudinal view); lmt(tv) - lateral microtubules (transverse view); $\mathrm{n}$ - nucleus; pc - places of connection (of transition fibers to the plasmalemma); tf - transition fiber.

Fig. 7. A-H) Transmission electron micrographs of consecutive transverse sections through the flagellar apparatus of Oscarella balibaloi.

Abbreviations: bf - basal foot; c - centriole; fm - fibrillar material; $\mathrm{k}$ - kinetosome; lmt - lateral microtubules; $\mathrm{tf}$ - transition fiber.

Fig. 8. Schematic representation of Oscarella balibaloi kinetid in lateral view.

Abbreviations: ag- axial granule; bf - basal foot; c - centriole; edm - electron-dense material (proposal); $\mathrm{fb}$ - fibrillar bridge between centriole and kinetosome; $\mathrm{fl}$ - flagellum; fr - fibrillar root; $\mathrm{Ga}$ - Golgi apparatus; $\mathrm{k}$ - kinetosome; lfr - lateral fibrillar root; lmt - lateral microtubules; $\mathrm{n}$ - 
nucleus; $1 \mathrm{~b}$ - lattice body (proposal); tf - transition fiber.

Fig. 9. Transmission electron micrographs from series of longitudinal sections through the flagellar apparatus in different Oscarellidae species. A) Oscarella rubra; B) O. bergenensis; C) $O$. tuberculata; D) O. carmela; E) O. viridis; F) O. microlobata: G) O. malakhovi; H) O. nicolae; I) O. kamchatkensis; J) O. pearsei; K) Pseudocorticium jarrei.

Abbreviations: fr - fibrillar root; Ga - Golgi apparatus; $\mathrm{k}$ - kinetosome; $\mathrm{mv}$ - microvilli; $\mathrm{n}$ nucleus.

Fig. 10. Bayesian phylogenetic tree of the family Oscarellidae based on concatenated dataset (28S, $18 \mathrm{~S}$ and COI loci). Numbers above branches indicate the posterior probabilities $(>0.9)$, numbers below branches indicate bootstrap values $(>70)$. Each clade with similar kinetid structure is highlighted in color. 
Table 1. Sequences used for the phylogenetic analysis with information on GB accession numbers

\begin{tabular}{|c|c|c|c|c|}
\hline \multirow{2}{*}{ Species } & \multicolumn{3}{|c|}{ GenBank accession number } & \multirow{2}{*}{ References } \\
\hline & $28 \mathrm{~S}$ & $18 \mathrm{~S}$ & $\mathrm{COI}$ & \\
\hline \multirow[t]{2}{*}{ Oscarella balibaloi } & \multirow[t]{2}{*}{-} & \multirow[t]{2}{*}{ JX462763 } & \multirow[t]{2}{*}{ KY682865 } & Gazave et al., 2013; \\
\hline & & & & Ereskovsky et al., 2017 \\
\hline Oscarella bergenensis & JX462771 & JX462768 & - & Gazave et al., 2013 \\
\hline \multirow{3}{*}{ Oscarella carmela } & \multirow{3}{*}{ KY513287 } & \multirow{3}{*}{ EU702422 } & \multirow{3}{*}{ EF081250 } & Lavrov et al., 2008 \\
\hline & & & & Wang, Lavrov, 2008 \\
\hline & & & & Ereskovsky et al., 2017 \\
\hline Oscarella filipoi & - & - & MG009508 & Pérez and Ruiz, 2018 \\
\hline Oscarella kamchatkensis & JX462781 & JX462762 & - & Gazave et al., 2013 \\
\hline Oscarella lobularis & HM118549 & HM118536 & KY682864 & $\begin{array}{l}\text { Gazave et al., 2010; } \\
\text { Ereskovsky et al., } 2017\end{array}$ \\
\hline Oscarella malakhovi & HM118550 & HM118537 & HQ269364 & Gazave et al., 2010 \\
\hline Oscarella microlobata & HM118551 & HM118538 & HQ269355 & Gazave et al., 2010 \\
\hline Oscarella nicolae & JX462770 & JX462769 & - & Gazave et al., 2013 \\
\hline Oscarella pearsei & $-*$ & $-*$ & KY682864 & Ereskovsky et al., 2017 \\
\hline Oscarella rubra & JX462773 & JX462765 & - & Gazave et al., 2013 \\
\hline Oscarella tuberculata & JX462777 & JX462761 & JX963640 & Gazave et al., 2013 \\
\hline Oscarella viridis & - & JX462764 & HQ269358 & Gazave et al., 2010, 2013 \\
\hline Oscarella zoranja & - & - & MG009501 & Pérez and Ruiz, 2018 \\
\hline
\end{tabular}




\begin{tabular}{|c|c|c|c|c|}
\hline Pseudocorticium jarrei & HM118552 & HM118539 & HQ269357 & Gazave et al., 2010 \\
\hline Corticium candelabrum & HM118553 & HM118540 & HQ269363 & Gazave et al., 2010 \\
\hline \multirow[t]{3}{*}{ Plakortis halichondrioides } & HM118557 & HM118543 & KP972554 & Gazave et al., 2010 \\
\hline & & & & Vicente et al., 2014 \\
\hline & & & & Gazave et al., 2010 \\
\hline \multirow[t]{3}{*}{ Plakinastrella onkodes } & HM118562 & HM118548 & KU674372 & \\
\hline & & & & Ruiz et al., 2017 \\
\hline & & & & Manuel et al., 2003 \\
\hline Leucaltis clathria & JQ272302 & AF452016 & - & \\
\hline
\end{tabular}

Voigt et al., 2012

*Sequences EF654526 (28S), EF654519, KY513286 (18S) under the name Oscarella pearsei in GenBank belong to $O$. carmela (see page 6). 